\title{
The determinants of chronic bronchitis in Aboriginal children and youth
}

\author{
Alomgir Hossain $\mathrm{PhD}^{1}$, Stephanie Konrad MSc${ }^{1}$, James A Dosman MD², \\ Ambikaipakan Senthilselvan $\mathrm{PhD}^{3}$, Jesse McCrosky MSc ${ }^{1}$, Punam Pahwa $\mathrm{PhD}^{1,2}$
}

\begin{abstract}
A Hossain, S Konrad, JA Dosman, et al. The determinants of chronic bronchitis in Aboriginal children and youth. Can Respir J 2012;19(6):e75-e80.
\end{abstract}

BACKGROUND: There is limited knowledge concerning chronic bronchitis (CB) in Canadian Aboriginal peoples.

OBJECTIVE: To determine the prevalence (crude and adjusted) of $\mathrm{CB}$ and its associated risk factors in Canadian Aboriginal children and youth six to 14 years of age.

METHODS: Data from the cross-sectional Aboriginal Peoples Survey were analyzed in the present study. Logistic regression analysis was used to determine risk factors influencing the prevalence of $\mathrm{CB}$ among Aboriginal children and youth. The balanced repeated replication method was used to compute standard errors of regression coefficients to account for clustering inherent in the study design. The outcome of interest was based on the question: "Have you been told by a doctor, nurse or other health professional that you have chronic bronchitis?" Demographics, environment and population characteristics (predisposing and enabling resources) were tested for an association with $\mathrm{CB}$.

RESULTS: The prevalence of CB was $3.1 \%$ for boys and $2.8 \%$ for girls. Other significant risk factors of CB were age (OR 1.38 [95\% CI 1.24 to 1.52] for 12 to 14 year olds versus six to eight year olds), income (OR 2.28 [95\% CI 2.02 to 2.59 ] for income category $<\$ 25,000 /$ year versus $\geq \$ 85,000 /$ year), allergies (OR 1.96 [95\% CI 1.78 to 2.16] for having allergies versus no allergies), asthma (OR 7.61 [ 95\% CI 6.91 to 8.37] for having asthma versus no asthma) and location of residence (rural/urban and geographical location). A significant two-way interaction between sex and body mass index indicated that the relationship between the prevalence of $\mathrm{CB}$ and body mass index was modified by sex.

DISCUSSION: The prevalence of CB was related to well-known risk factors among adults, including older age and lower annual income.

Key Words: Aboriginal children and youth; BRR; Chronic bronchitis; Complex survey

Canada experiences significant health disparities between Aboriginal and non-Aboriginal peoples, particularly affecting the health of children and youth $(1,2)$.

The Aboriginal population, as defined for the Aboriginal Peoples Survey (APS), consists of persons belonging to either the 'Aboriginal identity' population or the 'Aboriginal ancestry' population. Aboriginal identity refers to persons who report identifying with at least one Aboriginal group (North American Indian, Métis or Inuit, and/or those who report being a Treaty Indian or a Registered Indian, as defined by the Indian Act of Canada, and/or those who report being members of an Indian band or First Nation). Aboriginal ancestry refers to persons who report at least one Aboriginal ancestry (North American Indian, Métis or Inuit) $(3,4)$.

Bronchitis is one such condition that disproportionately affects Aboriginal children and youth. In 2002/2003, chronic bronchitis (CB) was one of the most frequent long-term chronic conditions among Aboriginal children living on reserves (5). Among Aboriginal

\section{Les déterminants de la bronchite chronique chez les enfants et adolescents autochtones}

HISTORIQUE : Les connaissances sont limitées à l'égard de la bronchite chronique $(\mathrm{BC})$ au sein des peuples autochtones canadiens.

OBJECTIF : Déterminer la prévalence (brute et rajustée) de BC et ses facteurs de risque connexes chez les enfants et adolescents autochtones canadiens de six à 14 ans.

MÉTHODOLOGIE : Les chercheurs ont analysé les données de l'Enquête auprès des peuples autochtones, une étude transversale. Ils ont utilisé l'analyse de régression logistique pour déterminer les facteurs de risque influant sur la prévalence de BC chez les enfants et adolescents autochtones. Grâce à la méthode de répétition compensée, ils ont calculé les écarts-types des coefficients de régression afin de tenir compte du regroupement inhérent à la méthodologie de l'étude. Le résultat d'intérêt se fondait sur la question : «Est-ce qu'un médecin, une infirmière ou un autre professionnel de la santé vous a informé que vous avez une bronchite chronique? » Les chercheurs ont vérifié les caractéristiques démographiques, environnementales et en population (ressources favorisantes et habilitantes) pour établir une association avec la BC.

RÉSULTATS : La prévalence de BC s'élevait à 3,1\% pour les garçons et à 2,8\% pour les filles. Les autres facteurs de risque significatifs de $\mathrm{BC}$ étaient l'âge (RRR 1,38 [95 \% IC 1,24 à 1,52] chez les 12 à 14 ans par rapport aux six à huit ans), le revenu (RRR 2,28 [95 \% IC 2,02 à 2,59] pour une catégorie de revenu inférieure à 25000 \$/année par rapport à 85000 \$/année ou plus), les allergies (RRR 1,96 [95\% IC 1,78 à 2,16] pour la présence d'allergies par rapport à l'absence d'allergies), l'asthme (RRR 7,61 [95 \% IC 6,91 à 8,37] pour la présence d'asthme par rapport à l'absence d'asthme) et le lieu de résidence (milieu rural ou urbain et emplacement géographique). Une interaction bidirectionnelle significative entre les sexes et l'indice de masse corporelle ont indiqué que le lien entre la prévalence de $\mathrm{BC}$ et l'indice de masse corporelle était modifié par le sexe.

EXPOSÉ : La prévalence de BC était liée à des facteurs de risque bien connus chez les adultes, y compris un âge plus avancé et un revenu annuel plus faible.

youth living on reserves, $\mathrm{CB}$ was among the top five most frequently reported diseases (5). A review suggested that respiratory tract infections, such as bronchitis, are not only more frequent but also more severe among Aboriginal children (6).

Various factors significantly associated with the prevalence and incidence of respiratory symptoms and bronchitis, including smoking, low family income, poor schooling and inadequate housing (such as living in houses with dampness and or mold), have been shown to be more prevalent among Aboriginal peoples (7-9). Smoking, a major risk factor for lung diseases in Aboriginal peoples, is highly prevalent among Aboriginal adolescents, with rates reported to be as high as $82 \%$ (10). Along with the high smoking rates in Aboriginal adults (11), Aboriginal children are highly likely to be exposed to tobacco smoke. Census metropolitan areas reported 57\% of First Nations, $45 \%$ of Inuit and $42 \%$ of Metis children were living in low-income families; this is compared with $21 \%$ for non-Aboriginal children (12). In 2006, Aboriginals were one-half as likely to complete high

${ }^{1}$ Department of Community Health and Epidemiology; ${ }^{2}$ Canadian Centre for Health and Safety in Agriculture, University of Saskatchewan, Saskatoon, Saskatchewan; ${ }^{3}$ Department of Public Health Sciences, School of Public Health, University of Alberta, Edmonton, Alberta

Correspondence: Dr Punam Pahwa, Canadian Centre for Health and Safety in Agriculture, University of Saskatchewan, 103 Hospital Drive,

Saskatoon, Saskatchewan S7N OW8. Telephone 306-966-7941, fax 306-966-7920, e-mail pup165@mail.usask.ca 
school compared with the general Canadian population (13). Lower education is often associated with socioeconomic status, which may be correlated to lower income and poor housing conditions. In 2006, Aboriginal children (Inuit, 29\%; First Nations, 18\%; Metis, $15 \%$ ) were more likely to be living in homes requiring major repairs, compared with $8 \%$ of non-Aboriginal children (12). The Inuit were also six times more likely than non-Aboriginal children to live in crowded homes (43\% compared with $7 \%$ ). Poor housing conditions are often associated with dampness and mold, which may lead to adverse respiratory outcomes $(14,15)$.

The present study hypothesized that demographic, environmental and population characteristics (predisposing as well as enabling resources) were associated with respiratory symptoms and CB. This hypothesis was tested by analyzing the 2006 Statistics Canada APS dataset. To date, the rates of $\mathrm{CB}$ and the determinants of $\mathrm{CB}$ in Canadian Aboriginal people have not been well established. Such information is critical to improving the health of Canadian Aboriginals. Accordingly, the objective of the present study was to determine the prevalence of $\mathrm{CB}$ and associated risk factors in Canadian Aboriginals six to 14 years of age.

\section{METHODS}

Study population and data sources

The 2006 APS was a national cross-sectional survey conducted from October 2006 through March 2007 by Statistics Canada in partnership with Aboriginal organizations (16). The target population of the APS survey was Aboriginal peoples (Aboriginal peoples living off reserve, Métis and Inuit) six years of age and older living in urban, rural and northern locations throughout Canada, identified through the 2006 Census questionnaire. The postcensal survey consisted of 48,921 participants and included information on Aboriginal identity and ancestry, education, language, labour activity, income, health, communication technology, mobility, housing and family background. The survey provided valuable data on Aboriginals six years of age and older. Details of this sampling design can be found elsewhere (16). Data were collected via self-administered questionnaires or interviews over the telephone or in person. Either the child or the parent/guardian or another family member answered the questions pertaining to the child.

In the present study, participants six to to 14 years of age were considered for analysis. The University of Saskatchewan Research Ethics Board (Saskatoon, Saskatchewan) approved the present research (BIO\#09-219). Permission to access the data was obtained from Statistics Canada and all analyses were conducted within the Statistics Canada Research Data Centre located at the University of Saskatchewan.

\section{Measures}

The APS included a set of questions designed to determine/investigate the chronic conditions of its Aboriginal participants. The variables used for the analysis are defined below.

\section{Outcome}

The outcome variable in the present study was the presence or absence of CB. The information collected on chronic health conditions was based on the question: "Which, if any, of the following long-term conditions or health problems does__ have that have been diagnosed by a doctor, nurse or health professional?" (16). One of the options in the list of chronic conditions was 'bronchitis', which was used for an outcome variable.

\section{Explanatory factors}

The prevalence of $\mathrm{CB}$ involves an interplay among several factors, such as demographic, socioeconomic and environmental variables, and the interactions between them. Thus, covariates of interest were demographic variables, environmental variables, health variables and enabling resources. Demographic variables consisted of age, sex and ethnicity. Age was divided into three groups: six to eight years; nine to 11 years; and 12 to 14 years. Ethnicity included three categories:
North American Indians, Inuit and Métis. Environmental variables consisted of location of residence, size of residence and geographical area. Location of residence had two categories: rural or urban. Geographical area was a nominal variable with eight categories: Atlantic (Halifax, Newfoundland and Labrador, New Brunswick and Prince Edward Island); British Columbia; Alberta; Saskatchewan; Manitoba; Quebec; and Ontario. Health-related variables consisted of chronic health conditions including the absence or presence of asthma and allergies, and body mass index (BMI). BMI was calculated based on the Centers for Disease Control and Prevention (Georgia, USA) guidelines for BMI for Children and Teens based on sex- and agestandardized percentiles; it included the categories underweight, normal weight, at risk of overweight and overweight. Enabling resources consisted of socioeconomic status, health services and social support. Socioeconomic status variables consisted of the education and income of the parent or guardian completing the form. Education had five categories: university degree, some university, high school completed, some high school, and elementary or less. Annual household income consisted of five categories: $<\$ 25,000 ; \$ 25,000$ to $\$ 44,999 ; \$ 45,000$ to $\$ 64,999 ; \$ 65,000$ to $\$ 84,999$; and $\geq \$ 85,000$.

\section{Statistical analysis}

The percentage of respondents reporting CB and risk factors was calculated. Appropriately weighted variables computed by methodologists of Statistics Canada were used in all analyses to ensure that the final estimates were representative of the surveyed population. Weighted multiple logistic regression modelling techniques based on a maximum likelihood was used to test association of risk factors of CB. The balanced repeated replication resampling technique was used to estimate the standard errors of regression coefficients to account for clustering inherent in the study design of the cross-sectional complex survey. A significance level of $\alpha=0.05$ was set. All two-way interactions were examined. The results of the models are presented as ORs with associated 95\% CIs. SAS version 9.2 (SAS Institute, USA) and STATA version 11 (StataCorp, USA) software were used to conduct all analyses.

\section{Crude prevalence of $\mathrm{CB}$}

\section{RESULTS}

The crude prevalence of $\mathrm{CB}$ was $3.1 \%$ among boys and $2.8 \%$ among girls. The prevalence of $\mathrm{CB}$ consistently increased as age increased: $2.4 \%$ among six to eight years olds; $2.7 \%$ among nine to 11 year olds; and $3.63 \%$ among 12 to 14 year olds. The prevalence of $\mathrm{CB}$ was highest in the region of Quebec (6.1\%) and lowest in Alberta (1.2\%). A slightly higher prevalence was also noted in urban residents compared with rural residents $(3.2 \%$ versus $2.3 \%$, respectively). The prevalence of $\mathrm{CB}$ was also highest among children with lower household income and education. Individuals with allergies had a prevalence of $7.5 \%$, much higher than those with no reported allergies (0.3\%). Similarly, among individuals with asthma, the prevalence of $\mathrm{CB}$ was $12.26 \%$. A slight increase in the prevalence of $\mathrm{CB}$ was also noted in those with a higher BMI. Table 1 summarizes both the prevalence and OR for CB.

\section{Adjusted prevalence of CB}

Table 2 summarizes all variables that were found to be significant predictors of CB based on four different multivariate models. These models were as follows: model I, with all selected predictors (based on $\mathrm{P}<0.20$ in Table 1) without allergies and asthma; model II, with all selected predictors including asthma; model III, with all selected predictors including allergies; and model IV, with all selected predictors including allergies and asthma. Results based on model IV were discussed because all selected variables, allergies and asthma were significant at $\mathrm{P}<0.05$. Girls had a lower $\mathrm{OR}$ of having $\mathrm{CB}$ than boys (OR 0.33 [ $95 \%$ CI 0.24 to 0.45$]$ ). Older individuals ( 12 to 14 years) were also more likely to report $\mathrm{CB}$ compared with those six to eight years of age (OR 1.38 [95\% CI 1.24 to 1.52]). Household income was inversely associated with CB. An annual household income $<\$ 25,000$ was associated with a 2.3 (95\% CI 2.02 to 2.59 ) times greater odds having CB 
TABLE 1

Characteristics of Aboriginal children stratified according to self-reported chronic bronchitis

\begin{tabular}{|c|c|c|c|}
\hline & \multicolumn{2}{|c|}{ Chronic bronchitis, \% } & \multirow[b]{2}{*}{ OR $(95 \% \mathrm{Cl})$} \\
\hline & Yes & No & \\
\hline \multicolumn{4}{|c|}{ Demographic Information } \\
\hline \multicolumn{4}{|l|}{ Sex } \\
\hline Male & 3.12 & 96.88 & - \\
\hline Female & 2.75 & 97.25 & $0.88(0.66-1.16)$ \\
\hline \multicolumn{4}{|l|}{ Age group, years } \\
\hline $6-8$ & 2.38 & 97.62 & - \\
\hline $9-11$ & 2.73 & 97.27 & $1.15(0.81-1.62)$ \\
\hline $12-14$ & 3.63 & 96.77 & $1.54(1.11-2.15)$ \\
\hline \multicolumn{4}{|l|}{ Residence } \\
\hline Urban & 3.21 & 96.79 & - \\
\hline Rural & 2.30 & 97.70 & $0.71(0.54-0.94)$ \\
\hline \multicolumn{4}{|c|}{ Geographical area (Canada) } \\
\hline Atlantic & 3.19 & 96.81 & - \\
\hline Quebec & 6.10 & 93.90 & $1.96(1.29-2.95)$ \\
\hline Ontario & 3.14 & 96.86 & $0.98(0.63-1.52)$ \\
\hline Manitoba & 2.34 & 97.66 & $0.72(0.42-1.23)$ \\
\hline Saskatchewan & 2.82 & 97.18 & $0.87(0.55-1.38)$ \\
\hline Alberta & 1.19 & 98.81 & $0.36(0.20-0.64)$ \\
\hline British Columbia & 2.19 & 97.81 & $0.68(0.42-1.10)$ \\
\hline \multicolumn{4}{|l|}{ Socioeconomic status } \\
\hline \multicolumn{4}{|c|}{ Educational attainment of guardian } \\
\hline$\leq$ Elementary & 20.73 & 79.27 & - \\
\hline Some high school & 3.47 & 96.53 & $1.33(0.59-3.03)$ \\
\hline $\begin{array}{l}\text { High-school } \\
\text { completed }\end{array}$ & 3.34 & 96.66 & $1.29(0.58-2.89)$ \\
\hline Some university & 2.69 & 97.31 & $1.02(0.43-2.40)$ \\
\hline University & 2.03 & 97.97 & $0.77(0.32-1.80)$ \\
\hline \multicolumn{4}{|c|}{ Household income/year, \$ } \\
\hline$\geq 85,000$ & 1.44 & 98.56 & - \\
\hline $65,000-84,999$ & 2.28 & 97.72 & $1.58(0.93-2.68)$ \\
\hline $45,000-64,999$ & 3.34 & 96.66 & $2.35(1.49-3.71)$ \\
\hline $25,000-44,999$ & 4.32 & 95.68 & $3.07(2.03-4.63)$ \\
\hline$<25,000$ & 3.54 & 96.46 & $2.50(1.62-3.85)$ \\
\hline \multicolumn{4}{|l|}{ Health-related } \\
\hline \multicolumn{4}{|l|}{ Asthma } \\
\hline No & 0.40 & 98.60 & - \\
\hline Yes & 12.26 & 87.74 & $9.88(7.28-13.40)$ \\
\hline \multicolumn{4}{|l|}{ Allergies } \\
\hline No & 0.25 & 99.75 & - \\
\hline Yes & 7.50 & 92.50 & $4.22(3.17-5.63)$ \\
\hline \multicolumn{4}{|c|}{ Body mass index categories } \\
\hline Underweight & 2.57 & 97.43 & - \\
\hline Normal weight & 2.95 & 97.05 & 1.15 (0.55-2.39) \\
\hline At risk of overweight & 3.15 & 96.85 & $1.23(0.57-2.71)$ \\
\hline Overweight & 3.23 & 96.77 & $1.27(0.60-2.70)$ \\
\hline
\end{tabular}

than an income $\geq \$ 85,000$. Rural residents were less likely to report $\mathrm{CB}$ compared with urban residents (OR 0.72 [95\% CI 0.67 to 0.78$]$ ). Geographical differences were also noted: compared with the Atlantic region, the prevalence of $\mathrm{CB}$ was significantly higher in Quebec and Ontario and significantly lower in the prairie provinces (Manitoba, Saskatchewan and Alberta) and British Columbia. When both variables (allergies and asthma) were included in the model (see model IV), they significantly increased the risk of CB. However, the strength of this association in model IV was weakened compared with the individual strength of association between: allergies and the prevalence of $\mathrm{CB}$

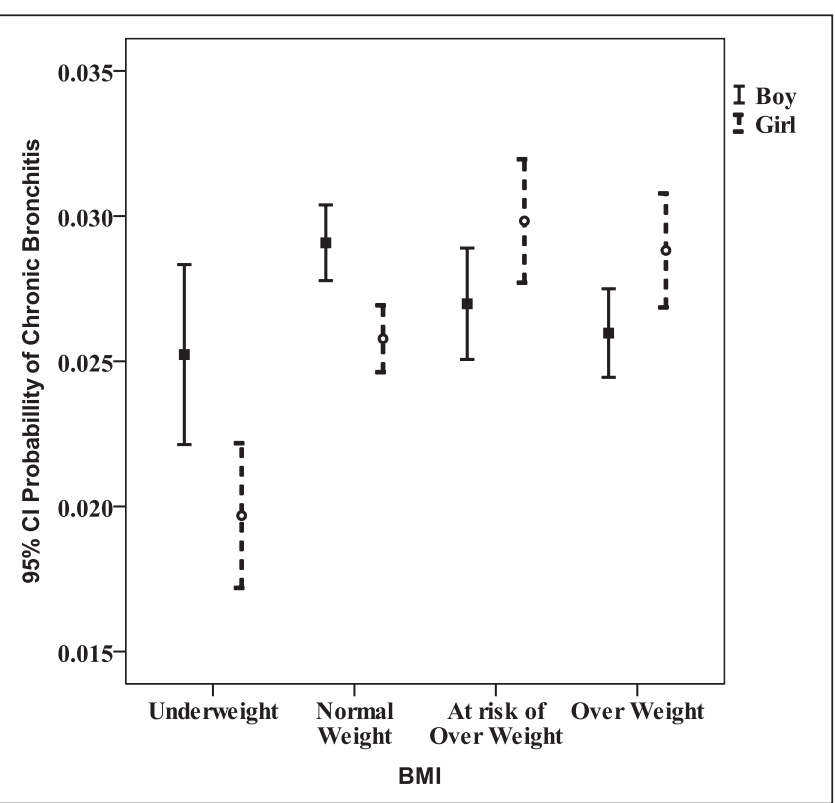

Figure 1) Probability of chronic bronchitis stratified according to sex and body mass index (BMI)

(from OR 3.91 [95\% CI 3.61 to 4.23] based on model III to OR 1.96 [95\% CI 1.78 to 2.16] based on model IV); and asthma and the prevalence of CB (from OR 9.76 [95\% CI 8.98 to 10.61] based on model II to OR 7.61 [95\% CI 6.91 to 8.37] based on model IV).

A significant interaction between sex and BMI was also found. Figure 1, an error bar graph, shows that among girls, an increase in weight was associated with a greater probability of CB. Among boys, however, this relationship was not present. There appeared to be no statistically significant difference among the four BMI categories.

\section{DISCUSSION}

Using a cross-sectional cohort, the present study determined the prevalence of $\mathrm{CB}$ and examined the associated risk factors among Aboriginal children. We found the prevalence of $\mathrm{CB}$ to be $3.1 \%$ among boys and $2.8 \%$ among girls. The prevalence was highest among individuals who had allergies. The multivariate analysis showed that older age, male sex, lower education attainment of the guardian, lower household income, having allergies, having asthma, residing in certain geographical areas and urban settings were significantly associated with self-reported physician-diagnosed CB. A two-way interaction between sex and BMI was also noted.

This significant two-way interaction between sex and BMI indicated that the probability of the development of $\mathrm{CB}$ is higher among boys with underweight and normal weight compared with girls, whereas lower among boys with at risk of overweight and overweight compared with girls.

Compared with our findings, the prevalence of self-reported physician-diagnosed CB was estimated to be $0.9 \%$ among Canadian children 12 to 19 years of age (17). Among Canadian Aboriginal adults, the prevalence of $\mathrm{CB}$ was found to be $7.2 \%$ among females and 5.0\% among males (18).

Similar to studies based on adult data, low income and poor schooling were found to be independently associated with CB (19-21). Income and education, indicators of the socioeconomic status of the child, suggests that other variables may be mediating this association (20). For instance, exposure to environmental tobacco smoke, an independent predictor of $\mathrm{CB}$, has been negatively associated with education (17).

Our study supports the evidence that allergies and asthma are associated with $\mathrm{CB}$ (17). 
TABLE 2

Logistic regression analysis of the prevalence of chronic bronchitis

\begin{tabular}{|c|c|c|c|c|}
\hline \multirow[b]{2}{*}{ Variable } & \multicolumn{4}{|c|}{ Model } \\
\hline & $\begin{array}{c}\text { I } \\
\text { (without allergies and asthma) }\end{array}$ & $\begin{array}{c}\text { II } \\
\text { (with asthma) }\end{array}$ & $\begin{array}{c}\text { III } \\
\text { (with allergies) }\end{array}$ & $\begin{array}{c}\text { IV } \\
\text { (with allergies and asthma) }\end{array}$ \\
\hline \multicolumn{5}{|l|}{ Sex } \\
\hline Male & - & - & - & - \\
\hline Female & $0.30(0.22-0.41)$ & $0.31(0.22-0.43)$ & $0.28(0.21-0.38)$ & $0.33(0.24-0.45)$ \\
\hline \multicolumn{5}{|l|}{ Age group, years } \\
\hline $6-8$ & - & - & - & - \\
\hline $9-11$ & $1.16(1.05-1.28)$ & $1.09(0.99-1.21)$ & $1.09(0.98-1.20)$ & $1.06(0.96-1.17)$ \\
\hline $12-14$ & 1.53 (1.39-1.69) & $1.45(1.31-1.61)$ & $1.38(1.25-1.52)$ & $1.38(1.24-1.52)$ \\
\hline \multicolumn{5}{|l|}{ Residence } \\
\hline Urban & - & - & - & - \\
\hline Rural & $0.68(0.49-0.65)$ & $0.74(0.67-0.80)$ & $0.68(0.62-0.73)$ & $0.72(0.67-0.78)$ \\
\hline \multicolumn{5}{|c|}{ Geographical area (Canada) } \\
\hline Atlantic & - & - & - & - \\
\hline Quebec & $2.16(1.91-2.44)$ & $1.85(1.63-2.11)$ & $1.99(1.77-2.26)$ & $1.79(1.58-2.04)$ \\
\hline Ontario & $1.19(1.05-1.35)$ & $1.22(1.07-1.38)$ & $1.20(1.06-1.36)$ & $1.22(1.07-1.38)$ \\
\hline Manitoba & $0.66(0.58-0.76)$ & $0.66(0.57-0.76)$ & $0.73(0.64-0.85)$ & $0.67(0.58-0.78)$ \\
\hline Saskatchewan & $0.72(0.64-0.82)$ & $0.81(0.71-0.92)$ & $0.87(0.76-0.99)$ & $0.87(0.76-0.99)$ \\
\hline Alberta & $0.40(0.33-0.47)$ & $0.38(0.32-0.45)$ & $0.43(0.37-0.51)$ & $0.38(0.33-0.45)$ \\
\hline British Columbia & $0.57(0.49-0.65)$ & $0.58(0.51-0.68)$ & $0.58(0.50-0.67)$ & $0.59(0.51-0.68)$ \\
\hline \multicolumn{5}{|c|}{ Household incomelyear, \$ } \\
\hline$\geq 85,000$ & - & - & - & - \\
\hline $65,000-84,999$ & $1.72(1.51-1.96)$ & $1.70(1.47-1.95)$ & $1.70(1.49-1.95)$ & $1.71(1.49-1.97)$ \\
\hline $45,000-64,999$ & $2.41(2.12-2.74)$ & $2.35(2.05-2.68)$ & $2.31(2.03-2.63)$ & $2.38(2.08-2.73)$ \\
\hline $25,000-44,999$ & $3.69(3.30-4.12)$ & $3.41(3.04-3.82)$ & $3.64(3.25-4.07)$ & $3.44(3.07-3.86)$ \\
\hline$<25,000$ & $2.44(2.17-2.74)$ & $2.28(2.02-2.58)$ & $2.28(2.02-2.57)$ & $2.28(2.02-2.59)$ \\
\hline \multicolumn{5}{|l|}{ Body mass index } \\
\hline Underweight & - & - & - & - \\
\hline Normal weight & $0.65(0.52-0.82)$ & $0.49(0.38-0.63)$ & $0.57(0.46-0.71)$ & $0.47(0.37-0.60)$ \\
\hline At risk of overweight & $0.60(0.47-0.76)$ & $0.45(0.34-0.59)$ & $0.53(0.42-0.67)$ & $0.44(0.34-0.57)$ \\
\hline Overweight & $0.74(0.59-0.92)$ & $0.49(0.38-0.63)$ & $0.66(0.53-0.82)$ & $0.48(0.38-0.62)$ \\
\hline \multicolumn{5}{|l|}{ Allergies } \\
\hline No & - & - & - & - \\
\hline Yes & - & - & $3.91(3.61-4.23)$ & $1.96(1.78-2.16)$ \\
\hline \multicolumn{5}{|l|}{ Asthma } \\
\hline No & - & - & - & - \\
\hline Yes & - & 9.76 (8.98-10.61) & - & 7.61 (6.91-8.37) \\
\hline \multicolumn{5}{|l|}{ Interaction } \\
\hline Sex*body mass index & - & - & - & - \\
\hline Girl*healthy weight & $2.97(2.14-4.12)$ & $3.62(2.53-5.17)$ & $3.55(2.57-4.89)$ & $3.60(2.55-5.09)$ \\
\hline Girl*At risk overweight & $4.64(3.25-6.63)$ & $5.64(3.83-8.31)$ & $5.27(3.71-7.49)$ & $5.37(3.69-7.82)$ \\
\hline Girl*overweight & $3.12(2.22-4.40)$ & $3.73(2.58-5.40)$ & $3.77(2.68-5.29)$ & $3.72(2.60-5.32)$ \\
\hline
\end{tabular}

Data presented as adjusted OR (95\% Cl)

Previous studies have found $\mathrm{CB}$ to be strongly associated with asthma among children. Carter et al (22) reported an OR of 6.4 (95\% CI 4.5 to 9.0) for having asthma for those with CB compared with those without $\mathrm{CB}$, after controlling for important confounders. Our study results (OR 7.61 [95\% CI 6.91 to 8.37) also indicate similar evidence for allergies (OR 1.96 [95\% CI 1.78 to 2.16]) and for asthma (OR 7.61 [95\% CI 6.91 to 8.37]).

Among adults, the link between obesity and chronic respiratory disease has become increasingly recognized. Obesity has been linked with $\mathrm{CB}$ and other respiratory dysfunctions $(23,24)$. The effects of obesity for children have been more extensively studied for asthma than $\mathrm{CB}$, where the association appears to be stronger among female than male subjects $(25,26)$. We noted a similar trend in our study.

Contrary to findings for Aboriginal adults, a rural setting was associated with a decreased OR of having CB.
There were several limitations to our study. In similar surveys, the measurement of CB lacked clinical accuracy, which could introduce misclassification. Asthma and bronchitis are inflammatory conditions that have similar symptoms (ie, constriction of airways in the lungs, difficult breathing, coughing and chest tightness); therefore, they can be difficult to distinguish (28). Hence, accurate estimation of the prevalence of $\mathrm{CB}$ in childhood is complicated due to the significant clinical overlap with asthma diagnosis (29). In the present study, CB was defined as self-reported physician-diagnosed CB. The definition of CB based on the question "Has a doctor ever said you had ... chronic bronchitis?" or a similar definition has been frequently used in medical studies $(29,30)$. It is possible that the APS may under-report the prevalence of bronchitis; however, the inclusion of nurse and other health professionals in the question is beneficial in populations that do not have access to a doctor. More research comparing $\mathrm{CB}$ prevalence rates 
based on APS data with other surveys and administrative databases (such as hospitalization data) is needed.

As the literature has reported, smoking $(31,32)$ and airborne pollutants (33-35) have been significantly associated with the prevalence of CB. Hence, another major limitation of the 2006 APS - children component is lack of information on personal and second hand smoke, and airborne pollutants

Diagnosis of chronic diseases may also be influenced by the availability and use of health care services, possibly causing systematic bias. In addition, all responses to the present survey were self-reported. It is well known that self-report may underestimate the prevalence of some risk factors such as weight and smoking status. Finally, the present survey only collected data on off-reserve First Nations people, and not those on reserve. Various statistics have shown significant differences between these two populations and, thus, these results may not necessarily be generalizable to all First Nations peoples. In addition, the Inuit were removed from the multivariate analysis, further limiting the generalizability of these findings to this population.

Our research provides a snapshot of $\mathrm{CB}$ and its determinants; nevertheless, additional analyses are needed to explore these associations, particularly how low socioeconomic status and BMI affect CB in children.

\section{REFERENCES}

1. MacMillan HL, MacMillan AB, Offord DR, Dingle JL. Aboriginal Health. CMAJ 1996;155:1569-78.

2. UNICEF Canada. Canadian Supplement to the State of the World's Children, 2009. Aboriginal children's health: Leaving no child behind. 2009 < www.unicef.ca/portal/Secure/Community/502/WCM/ HELP/take_action/Advocacy/Leaving\%20no\%20child\%20 behind\%2009.pdf> (Accessed July 26, 2010).

3. Statistics Canada. Aboriginal Peoples in Canada in 2006: Inuit, Metis and First Nations, 2006 Census. 2008. <www12.statcan.ca/ census-recensement/2006/as-sa/97-558/pdf/97-558-XIE2006001.pdf> (Accessed July 20, 2010).

4. Statistics Canada, User's guide to the Analytical Files for the 2006 Aboriginal Peoples Survey.

5. Health Canada. A statistical profile on the health of First Nations in Canada - Health service utilization in Western Canada, 2000. 2009. <www.hc-sc.gc.ca/fniah-spnia/pubs/aborig-autoch/index-eng. php> (Accessed June 1, 2010).

6. Fraser-Lee NJ, Hessel PA. Acute respiratory infections in the Canadian native Indian population: A review. Can J Public Health 1994;85:197-200.

7. Melia RJW, Chinn S, Rona RJ. Respiratory illness and home environment of ethnic groups. BMJ 1988;296:1438-41.

8. Cooreman J, Redon S, Levallois M, Liard R, Perdrizet S. Respiratory history during infancy and childhood and respiratory conditions in adulthood. Int Epidemiol 1990;19:621-7.

9. Bakke PS, Baste V, Hanoa R, Gulsvik A. Prevalence of obstructive lung disease in a general population: Relation to occupational title and exposure to some airborne agents. Thorax 1991;46:863-70.

10. Retnakaran R, Hanley AJ, Connelly PW, Harris SB, Zinman B. Cigarette smoking and cardiovascular risk factors among Aboriginal Canadian youth. CMAJ 2005;173:885-9.

11. Health Canada. Tobacco. Health Canada; 2004 [updated 2007 October 31, cited 2010 July 21]; <www.hc-sc.gc.ca/fniah-spnia/ substan/tobac-tabac/index-eng.php> (Accessed July 20, 2010).

12. Statistics Canada. Aboriginal Children's Survey, 2006. <www.statcan.gc.ca/pub/89-634-x/89-634-x2008001-eng.pdf> (Accessed July 26, 2010).

13. Statistics Canada. Educational portrait of Canada, 2006 Census. 2008. <www12.statcan.gc.ca/english/census06/analysis/education/ pdf/97-560-XIE2006001.pdf> (Accessed July 22, 2010).

14. Sin DD, Wells H, Svenson LW, Man SFP. Asthma and COPD among Aboriginals in Alberta, Canada. Chest 2002;121:1841-6.

15. Strachan DP, Sanders CH. Damp housing and childhood asthma: Respiratory effects of indoor air temperature and relative humidity. J Epidemiol Community Health 1989:43:7-14.

16. Statistics Canada. Aboriginal Peoples Survey (APS). 2009. <www.statcan.gc.ca/imdb-bmdi/3250-eng.htm> (Accessed July 22, 2010).
To our knowledge, the present study was the first to specifically examine associated factors for $\mathrm{CB}$ among Aboriginal children and youth. Our research provides information on the prevalence of $\mathrm{CB}$ and its determinants among Aboriginal children and youth based on a cross-sectional survey. Nevertheless, further analyses based on longitudinal data are required to investigate the causal relationship between various risk factors and $\mathrm{CB}$. Our study highlights the importance of reduction in BMI among this population of Aboriginal children and youth, particularly among females.

\section{CONCLUSION}

The present study showed that potentially preventable risk factors (low socioeconomic status and obesity) were significantly associated with CB after adjusting for other important covariables. Such information may be useful for designing and promoting preventive campaigns specifically for Aboriginal children and youth.

DISCLOSURES: The authors have no financial disclosures or conflicts of interest to declare.

17. Evans J, Chen Y. The association between home and vehicle environmental tobacco smoke (ETS) and chronic bronchitis in a Canadian population: The Canadian Community Health Survey, 2005. Inhalation Toxicol 2009;21:244-9.

18. Konrad S , Hossain A, Senthilselvan A, Dosman J, Punam P. Chronic bronchitis in Canadian Aboriginal adults. Chron Dis Can 2011 (In press).

19. Chen Y, Horne SL, McDuffie HH, Dosman JA. Combined effect of grain farming and smoking on lung function and the prevalence of chronic bronchitis. Int J Epidemiol 1991:20:416-23.

20. Menzes AM, Vicotry CG, Rigatto M. Prevalence and risk factors for chronic bronchitis in Pelotas, RS Brazil: A population based study. Thorax 1994:49:1217-21.

21. Pelkonen M. Smoking: Relationship to chornic bronchitis, chronic obstructive pulmonary disease and mortality. Curr Opin Pulm Med 2008:14:105-9.

22. Carter ER, Debley JS, Redding GJ. Chronic bronchitis in children: How much is due to asthma? Chest 2004;126:761S.

23. Guerra S, Sherrill DL, Bobadilla A, Martinez FD, Barbee RA. The relation of body mass index to asthma, chronic bronchitis and emphysema. Chest 2002;122:1256-63.

24. Poulain M, Doucet M, Major GC, et al. The effect of obesity on chronic respiratory diseases: Pathophysiology and therapeutic strategies. CMAJ 2006;174:1293-9.

25. Castro-Rodrigues JA, Holberg CJ, Morgan WJ, et al. Increased incidence of asthma-like symptoms in girls who become overweight or obese during the school years. Am J Respir Crit Care Med 2001;163:1344-9.

26. Figueroa-Munoz JI, Chinn S, Rona RJ. Association between obesity and asthma in 4-11 year old children in the UK. Thorax 2001;56:133-7.

27. CDC BMI guideline <http://apps.nccd.cdc.gov/dnpabmi> (Accessed July 20, 2010).

28. <www.livestrong.com/article/220387-differences-between-asthmabronchitis/) $>$ (Accessed July 20, 2010).

29. Meren M, Jannus-Pruljan L, Loit HM, et al Asthma, chronic bronchitis and respiratory symptoms among adults in Estonia according to a postal questionnaire. Respir Med 2001;95(12):954-64.

30. Pahwa P, Karunanayake, C, Willson PJ, et al; for the Saskatchewan Rural Health Study Team. Prevalence of chronic bronchitis in farming and non-farming rural residents in Saskatchewan. J Occup Environ Med (In Press).

31. Gergen PJ, Fowler JA, Maurer KR, Davis WW, Overpeck MD. The burden of environmental tobacco smoke exposure on the respiratory health of children 2 months through 5 years of age in the United States: Third national health and nutrition examination survey, 
1988 to 1994 . Pediatrics $1998 ; 101 ; \mathrm{e} 8 .<$ http://pediatrics. aappublications.org/content/101/2/e8.full.html>

(Accessed July 22, 2010).

32. Jaakkola JJK, Kosheleva AA, Katsnelson BA, Kuzmin SV, Privalova LI, Spengler JD. Prenatal and postnatal tobacco smoke exposure and respiratory health in Russian children. Respir Res 2006;7:48.

33. Cerveri I, Accordini S, Verlato G, et al; for the European Community Respiratory Health Survey (ECRHS) Study Group. Variations in the prevalence across countries of chronic bronchitis and smoking habits in young adults. Eur Respir J 2001;18:85-92.
34. Zock J-P, Sunyer J, Kogevinas M, Kromhout H, Burney P, Antó JM; The ECRHS Study Group. Occupation, chronic bronchitis, and lung function in young adults: An international study. Am J Respir Crit Care Med 2001;163:1572-7.

35. Ebbehøj NE, Hein HO, Suadicani P, Gyntelberg F. Occupational organic solvent exposure, smoking, and prevalence of chronic bronchitis - an epidemiological study of 3387 men. J Occup Environ Med 2008;50:730-5. 


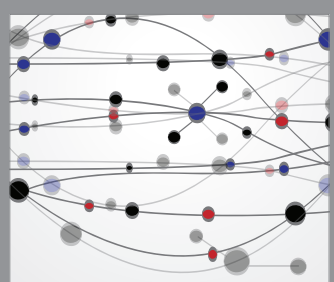

The Scientific World Journal
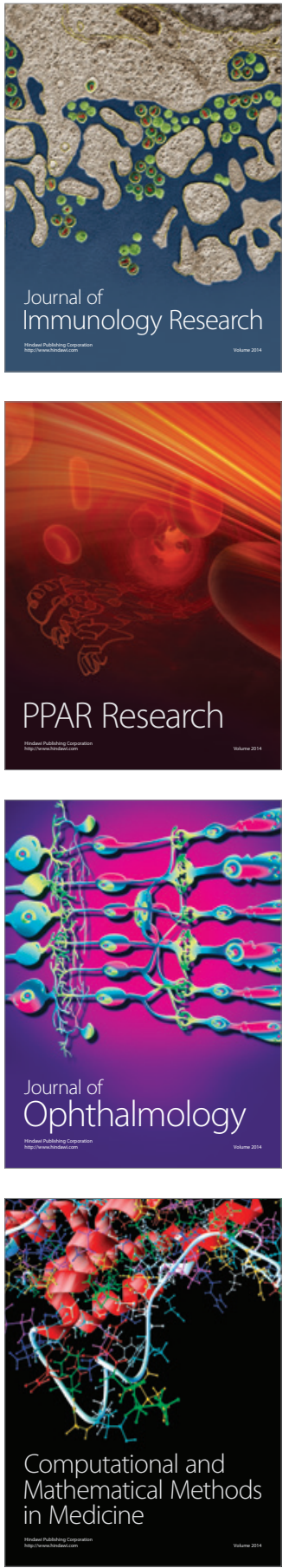

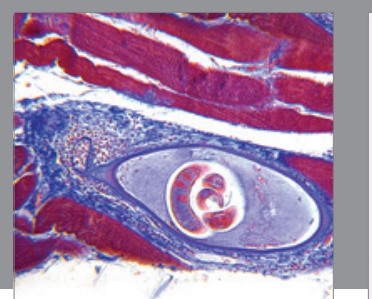

Gastroenterology Research and Practice

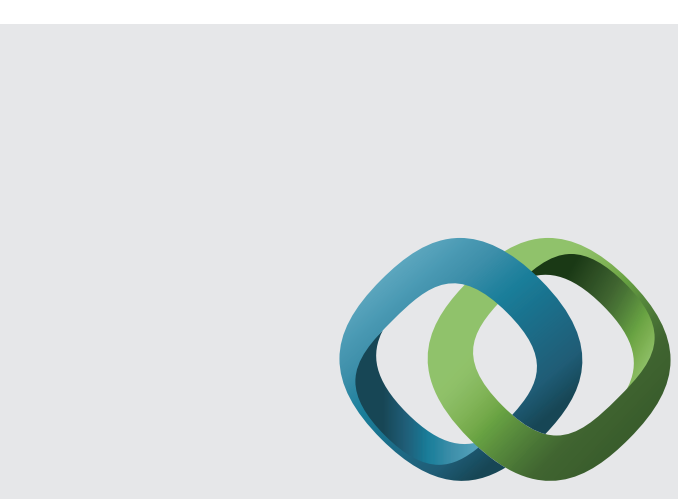

\section{Hindawi}

Submit your manuscripts at

http://www.hindawi.com
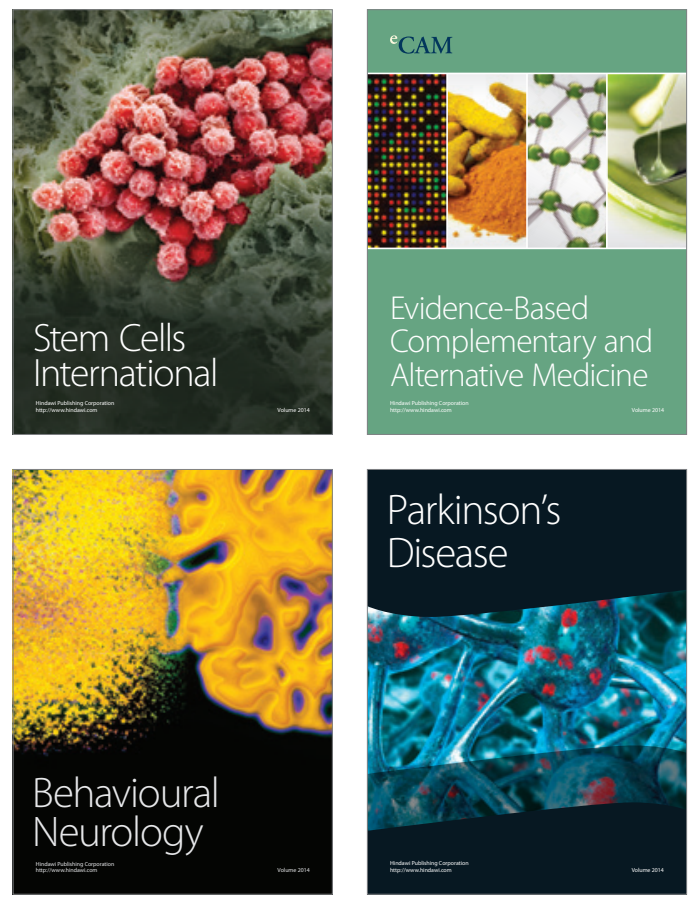
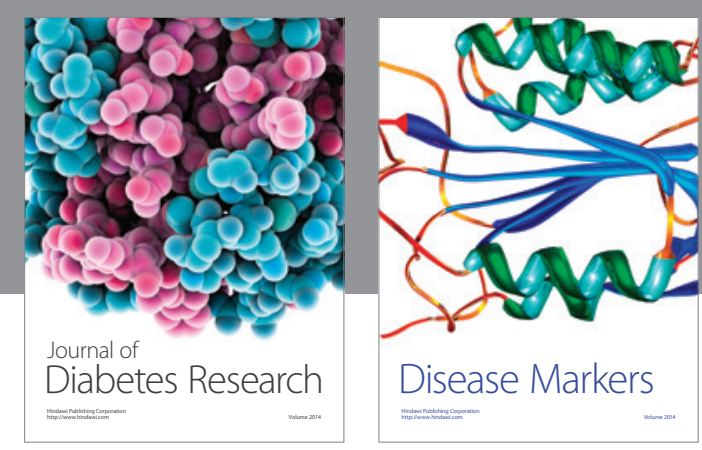

Disease Markers
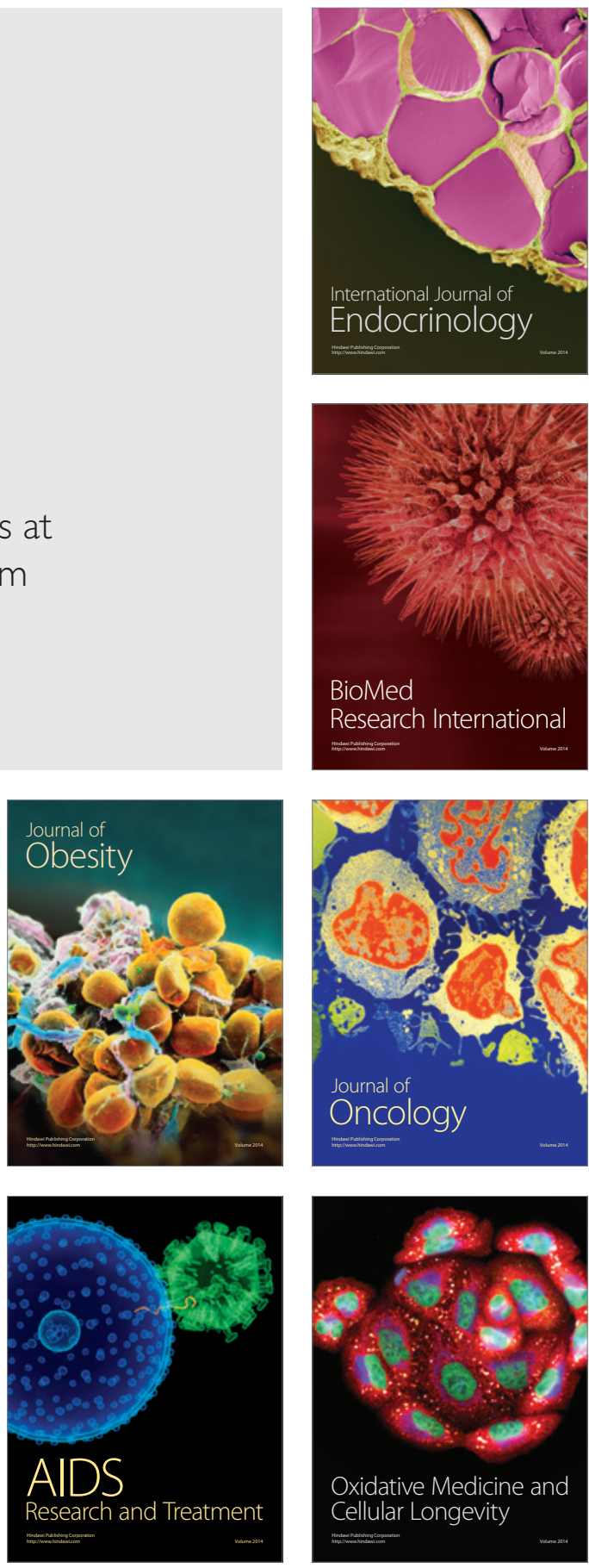